\title{
High Performance Sn-In Cathode for the Electrochemical Reduction of Carbon Dioxide to Formic Acid
}

\author{
Fajun $\mathrm{Li}^{1,2}$, Hua Zhang ${ }^{1}$, Shuai $\mathrm{Ji}^{1}$, Wei Liu ${ }^{3}$, Dong Zhang ${ }^{1}$, Chengdu Zhang ${ }^{1}$, \\ Jing Yang ${ }^{1}$, Fei Yang ${ }^{1}$, Lixu Lei ${ }^{1,2, *}$ \\ ${ }^{1}$ School of Chemistry and Chemical Engineering, Southeast University, Nanjing 211189, China \\ ${ }^{2}$ The Jiangsu Key Laboratory for Advanced Metallic Materials, Nanjing, 211189, China \\ ${ }^{3}$ Key Laboratory of Electrochemical Energy Storage Technology of Jiangsu Province, Shuangdeng \\ Group Co. Ltd. Taizhou, Jiangsu 225300, China \\ *E-mail: lixu.lei@ seu.edu.cn
}

doi: $10.20964 / 2019.05 .44$

Received: 3 January 2019 / Accepted: 1 March 2019 / Published: 10 April 2019

Both $\mathrm{Sn}$ and In have been potentiostatically co-deposited on the surface of $\mathrm{Cu}$ foam at different potentials to prepare $\mathrm{Sn}$-In bimetallic electrodes. Among them, the $\mathrm{Sn}_{42} \mathrm{In}_{58}$ electrode has excellent catalytic activity towards $\mathrm{CO}_{2}$ reduction to formic acid. At $-1.6 \mathrm{~V}$ versus $\mathrm{Ag} / \mathrm{AgCl}$, the formate Faradaic efficiency reaches its maximum, 88\%; and its space time yield reaches $309 \mu \mathrm{mol} \mathrm{h}^{-1} \mathrm{~cm}^{-2}$ at $-1.8 \mathrm{~V}$ versus $\mathrm{Ag} / \mathrm{AgCl}$. When it is used in the biomimetic electrochemical cell reported previously by us, a much higher space time yield, $468 \mu \mathrm{mol} \mathrm{h}^{-1} \mathrm{~cm}^{-2}$ is obtained.

Keywords: Electrochemical reduction, carbon dioxide, formate, tin-indium bimetallic catalyst, space time yield

\section{FULL TEXT}

(C) 2019 The Authors. Published by ESG (www.electrochemsci.org). This article is an open access article distributed under the terms and conditions of the Creative Commons Attribution license (http://creativecommons.org/licenses/by/4.0/). 